\title{
Fission Products Silver, Palladium, and Cadmium identification in Neutron-Irradiated SiC TRISO Particles Using a Cs-Corrected HRTEM
}

\author{
I. J. van Rooyen ${ }^{1 *}$, E. J. Olivier ${ }^{2}$ and J. H Neethling ${ }^{2}$ \\ ${ }^{I}$ Fuel Design and Development Department, Idaho National Laboratory \\ P.O. Box 1625, Idaho Falls ID, 83415-6188, USA \\ phone:+1-208-526-4199, isabella.vanrooyen@inl.gov \\ *Corresponding author \\ ${ }^{2}$ Centre for High Resolution Electron Microscopy, Department of Physics, \\ Nelson Mandela Metropolitan University, Port Elizabeth, South Africa
}

\begin{abstract}
Electron microscopy investigations of selected coated particles from the first advanced gas reactor experiment at Idaho National Laboratory provided important information on fission product distribution and chemical composition in the silicon-carbide $(\mathrm{SiC})$ layer. Silver precipitates were nano-sized, and therefore high-resolution transmission electron microscopy (HRTEM) was used to provide more information at the atomic level. Based on gamma-ray analysis, this particle which was irradiated to an average burnup of $19.38 \%$ fissions per initial metal atom, may have released as much as $10 \%$ of its available Ag-110m inventory during irradiation. The HRTEM investigation focused on silver, palladium, and cadmium due to interest in silver transport mechanisms and possible correlation with palladium and silver previously found. Palladium, silver, and cadmium were found to co-exist in some of the SiC grain boundaries and triple junctions. This study confirmed palladium both at inter and intragranular sites. Phosphor was identified in SiC grain boundaries and triple points.
\end{abstract}

\section{INTRODUCTION}

A detailed understanding of the silver $(\mathrm{Ag})$ transport mechanism in polycrystalline 3C-silicon-carbide ( $\mathrm{SiC})$ is important for design of advanced coated fuel particles for high-temperature reactors. A finding more than three decades ago, about Ag being released by intact tristructural isotropic (TRISO) particles has led to significant research efforts to determine an $\mathrm{Ag}$ transport mechanism in $\mathrm{SiC}$, because out-of-reactor experiments did not reveal any significant $\mathrm{Ag}$ migration in $\mathrm{SiC}$. Numerous $\mathrm{Ag}-110 \mathrm{~m}$ transport mechanisms (e.g., grain boundary diffusion, surface diffusion or vapor transport through interconnected nano-pores or nano-cracks, and palladium $[\mathrm{Pd}]$-assisted transport alongside grain boundaries) have been proposed from these out-of-pile experiments [1$10]$.

Researchers [5-7] annealed polycrystalline $\mathrm{SiC}$ in contact with a Pd-Ag compound out-of-pile and reported that $\mathrm{Pd}$ significantly enhanced the transport of $\mathrm{Ag}$ along grain boundaries in $\mathrm{SiC}$. It was also reported that $\mathrm{Ag}$ or an Ag-Si compound did not penetrate polycrystalline 3C-SiC in the absence of Pd. Recent research by O'Connell and Neethling [10] reported enhanced Pd-Ag transport along grain boundaries in bulk (i.e., SiC grown by Rohm and Haas and irradiated at Oak Ridge National Laboratory) neutron-irradiated polycrystalline SiC annealed at $1000^{\circ} \mathrm{C}$ (out-of-pile) compared to $\mathrm{Pd}-\mathrm{Ag}$ transport in unirradiated $\mathrm{SiC}$. In addition, $\mathrm{Pd}$ was also observed inside (i.e., at a distance of about $100 \mu \mathrm{m}$ from the grain boundary) $\mathrm{SiC}$ grains of high-fluence $\left(9.4 \times 10^{21} \mathrm{n} / \mathrm{cm}^{2}\right.$ at $1460^{\circ} \mathrm{C}$ ) irradiated samples. The neutron irradiation of $\mathrm{SiC}$ at high temperatures leads to the introduction of voids in rows along the $\{111\}$ planes, which was found to enhance the transport of Pd in the SiC grains. Void formation is aided by the presence of lattice faults such as stacking faults and twins that readily form in $\mathrm{SiC}$ on $\{111\}$ planes.

Although these individual studies are relevant to specific experimental conditions, no experimental verification of the role of Pd in Ag transport in actual neutron-irradiated SiC layers of TRISO-coated particles, which could be used to validate these out-of-pile hypotheses [11-13], has been reported to date.

Therefore, the first direct observation of $\mathrm{Ag}$ in $\mathrm{SiC}$ grain boundaries of neutron-irradiated, TRISO-coated particles from the first Advanced Gas Reactor (AGR-1) experiment by van Rooyen and co-workers [13] provided motivation to confirm or rule out some of these Ag transport mechanism hypotheses. This work showed the co-existence of $\mathrm{Ag}$ and cadmium $(\mathrm{Cd})$ in grain boundaries and the triple points of the neutronirradiated SiC. Pd was found separately in different grain boundaries and inside the SiC grains. These results prompted the Idaho National Laboratory analytical electron microscopy investigation on Pd and Ag transport in SiC layers from TRISO-coated particles. 
In this paper, analytical and high-resolution scanning transmission electron microscopy (STEM) was used to examine the microstructure and location of fission products (i.e., $\mathrm{Pd}, \mathrm{Ag}$, and $\mathrm{Cd}$ ) in $\mathrm{SiC}$ irradiated to an average fast fluence of $4.13 \times 10^{25} \mathrm{n} / \mathrm{m}^{2}$.

\section{MATERIAL AND METHODS}

\subsection{Material}

Initial results of the high-resolution electron microscopy examination of a coated particle from Compact 4-11 from AGR-1 are described in this section. The unique identification number of Compact 4-1-1 is based on the specific capsule, level, and stack number for each compact. Fig. 1 identifies the stack and position (or level) numbers in a particular capsule. Compact 4-1-1 refers to the compact in Capsule 4 at Level 1 of Stack 1. Capsule design and details of the AGR-1 experiment have been described in previous reports [14].

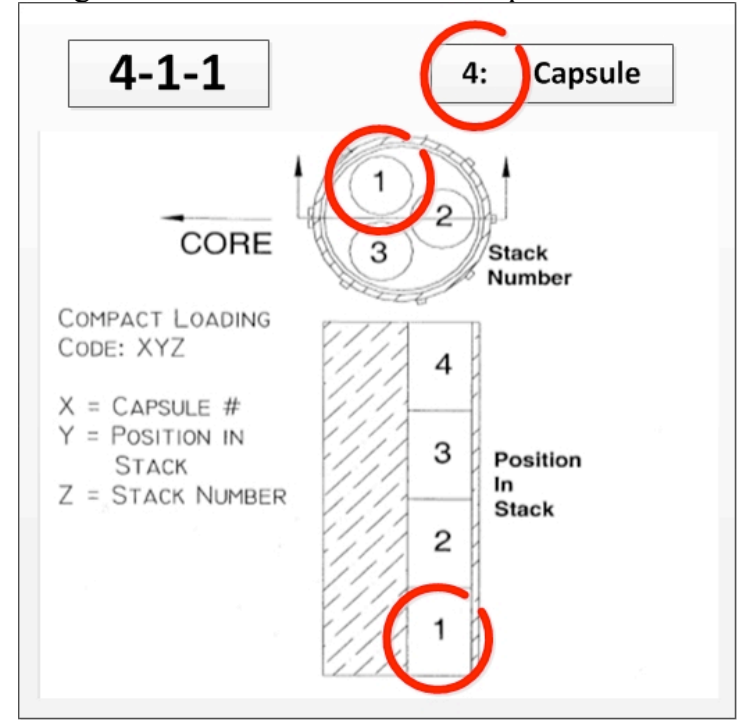

Fig. 1. Numbering scheme for AGR-1 Compact 4-1-1.

Compact 4-1-1 contains Variant 3 fuel particles that were fabricated by changing the fuel carrier gas composition for the $\mathrm{SiC}$ layer vapor deposition from $100 \%$ hydrogen to a $50 \%$ argon, $50 \%$ hydrogen mixture and the deposition temperature was lowered relative to the baseline (from 1500 to $1425^{\circ} \mathrm{C}$ ). This change was expected to reduce the potential for $\mathrm{SiC}$ defects formation resulting from uranium dispersion and provide a variation in $\mathrm{SiC}$ microstructure that may be less permeable to metallic fission products. The effect of the changed $\mathrm{SiC}$ fabrication parameters on the fission product transport and release is not yet fully determined as the advanced microscopy examination of the various variant fuel types are in progress. The fuel kernel is fabricated from low-enriched uranium oxycarbide with a diameter of approximately $350 \mu \mathrm{m}$ and a U-235 enrichment of approximately 19.7\%. Selected properties for the Variant 3 AGR-1 coated particles are shown in Table 1 [15].

Table 1. Selected properties (actual mean value \pm population standard deviation) for the Variant 3 AGR-1 coated particles [15].

\begin{tabular}{|l|l|l|}
\hline \multirow{2}{*}{ Coating Layer } & $\begin{array}{l}\text { Mean Value } \pm \text { Population Standard } \\
\text { Deviation }\end{array}$ \\
\cline { 2 - 3 } & Thickness $(\mu \mathrm{m})$ & Density $\left(\mathrm{mg} / \mathrm{m}^{3}\right)$ \\
\hline Buffer & $104.2 \pm 7.8$ & $1.10 \pm 0.04$ \\
\hline Inner pyrolytic carbon (IPyC) & $38.8 \pm 2.1$ & $1.904 \pm 0.013$ \\
\hline SiC & $35.9 \pm 2.1$ & $3.205 \pm 0.001$ \\
\hline Outer pyrolytic carbon (OPyC) & $39.3 \pm 2.1$ & $1.911 \pm 0.008$ \\
\hline
\end{tabular}

Compact 4-1-1 was irradiated to $19.38 \%$ fissions per initial metal atom average burnup; $1072{ }^{\circ} \mathrm{C}$ timeaveraged, volume-averaged temperature; $1182^{\circ} \mathrm{C}$ time-averaged peak temperature; and an average fast fluence of $4.13 \times 10^{21} \mathrm{n} / \mathrm{cm}^{2}$. Individual particles were gamma ray counted to measure the activity of various gamma ray emitting fission products. The retention of $\mathrm{Ag}-110 \mathrm{~m}$ in each particle is estimated by comparing the measured inventory to the predicted inventory normalized by the relative Cs-137 activity to reduce the influence of different kernel sizes on overall distribution (see [15] for details).

The measured-to-calculated ratio for 58 gamma ray counted particles from Compact 4 ranged from 0.075 to 1.45. Coated particle AGR1-411-030 was selected because it exhibited an average retention of Ag- $110 \mathrm{~m}$ under irradiation with a measured-to-calculated Ag-110m ratio of 0.90 (Fig. 2). Deconsolidation-leach-burn-leach data [15] indicate that the particles from Compact 4-1-1 released, on average, approximately 3\% of their inventory during irradiation, which was retained in the matrix. It has been concluded that, on average, there was relatively 
low release of Ag from the particles in this compact. Decay-corrected activity (in $\mathrm{Bq}$ ) for $\mathrm{Ag}-110 \mathrm{~m}$ measured by gamma ray counting of the AGR1-411-030 particle is $6.45 \times 10^{4}[15]$.

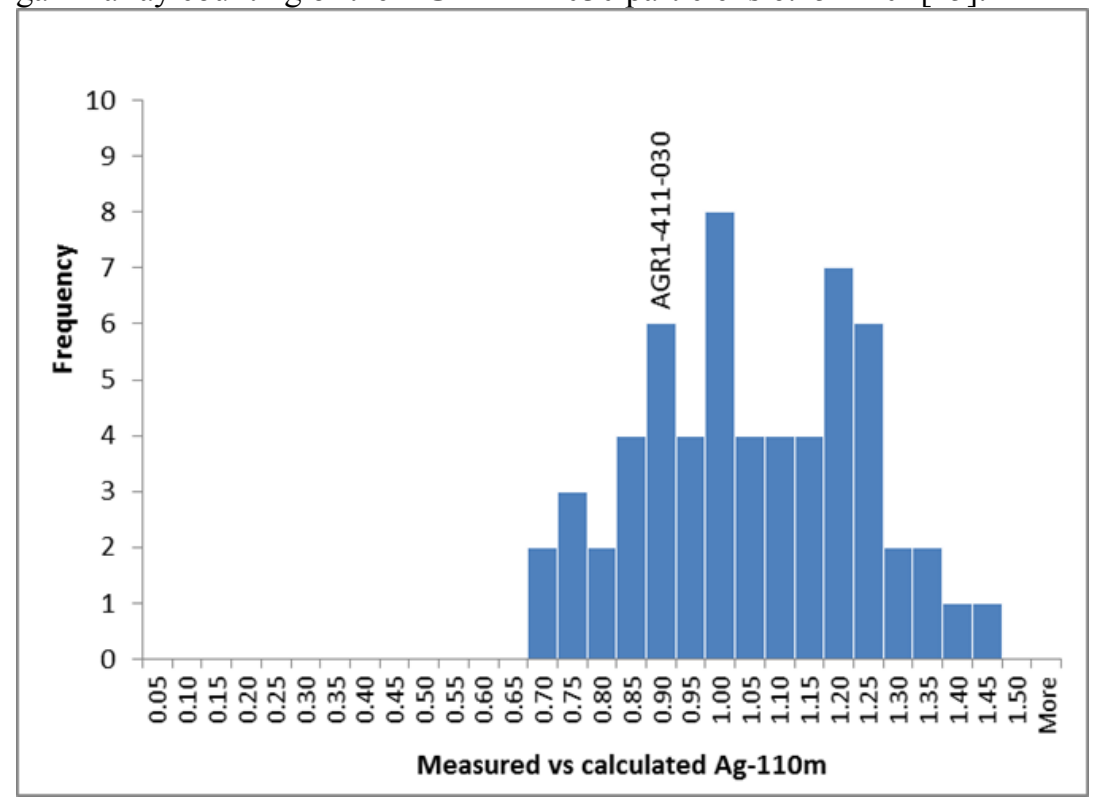

Fig. 2. Distribution of measured-to calculated Ag-110m activity ratios, normalized by the Cs-137 activity to account for variations in fissile content and burnup.

\subsection{Methods}

The TEM specimens were prepared at the Electron Microscopy Laboratory at Idaho National Laboratory's Materials and Fuels Complex, using the dual-beam Quanta 3D field emission gun (FEG) focused ion beam (FIB) (Fig. 3). FIB lamellas at position 1b, 1c, and 2 were extracted from locations perpendicular to the SiC-IPyC interface. Lamellas $1 \mathrm{~b}$ and 2 contain parts of both the IPyC and SiC layers, while FIB lamella 1c is from the outer interface between the $\mathrm{SiC}$ and OPyC layer, which is the furthest away from the IPyC-SiC interface. FIB lamella 1a contained only a small area of the $\mathrm{SiC}$ layer close to the IPyC-SiC interface and was cut parallel to the IPyC-SiC interface. Because lamella 1a contained only small areas of the SiC layer at the IPyC-SiC interface, it was not examined for this paper.

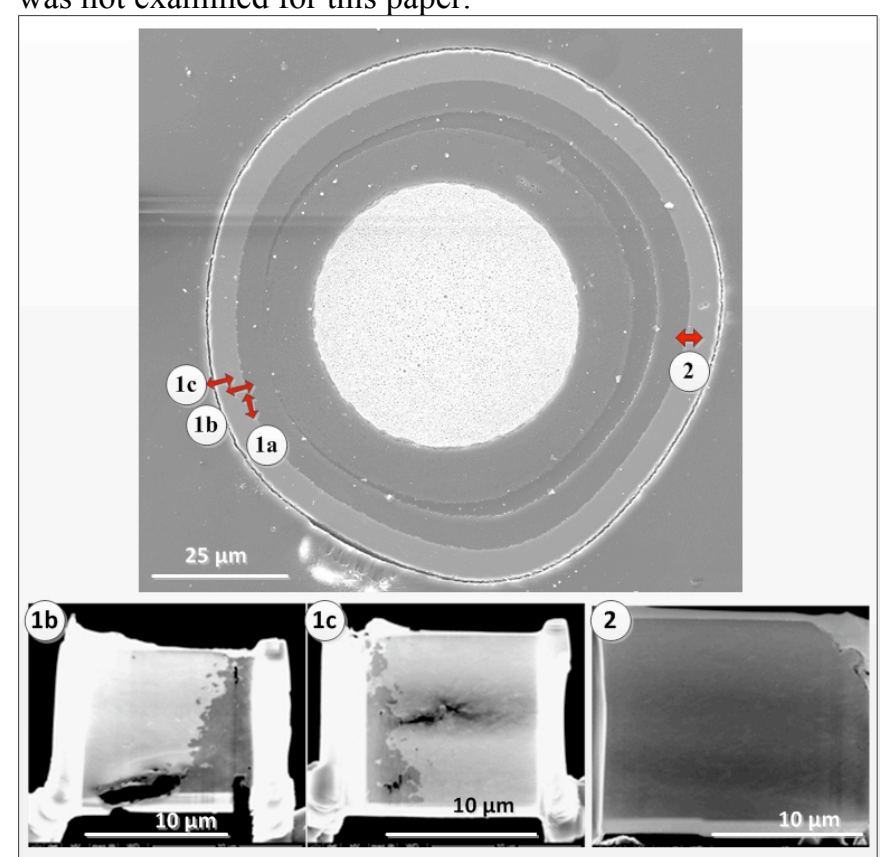

Fig. 3. Scanning electron microscope image showing the AGR1-411-030 FIB scanning electron microscope lamellas sectioned at positions $1 \mathrm{~b}, 1 \mathrm{c}$, and 2 as indicated on the cross section of the coated particle.

High-resolution transmission electron microscopy (HRTEM) and high-resolution STEM (HRSTEM) investigations were performed at the Nelson Mandela Metropolitan University in South Africa, using a double Cs-corrected JEOL ARM 200F operated at $200 \mathrm{kV}$. This microscope is equipped with two CEOS spherical 
aberration (Cs) correctors for correction in TEM and STEM modes and with an Oxford Instruments XMAX 80 electron dispersive spectroscopy (EDS) detector and Gatan quantum image filter with dual electron energy loss spectroscopy capabilities. The use of aberration corrected STEM in the analysis of the specimens arises from the relative increase in probe current density achieved as compared to uncorrected microscopes. Greater signal can be generated from a comparatively smaller area which results in the analysis of more localized areas in a shorter space of time.

Subsequent EDS analyses were performed with a JEOL Centurio EDS detector, which is a next-generation type Silicon Drift Detector (SDD) detector that has a chip area of $100 \mathrm{~mm}^{2}$ and an enhanced detector design that allows for significant improvement (about 300\%) in collection efficiency compared to previous detectors (such as the Oxford XMax 80). In the case of the JEOL Centurio, a collection angle of about $0.82 \mathrm{Sr}$ is specified when using the JEOL ARM 200F fitted with an ultra high resolution (UHR) pole piece. The Oxford XMax 80 fitted on the same configuration has a collection angle of about $0.21 \mathrm{Sr}$. The improved collection efficiency leads to better counting statistics over a shorter time period, which allows the detection of low concentrations of elements during the shorter analysis time before sample modification or contamination issues by the electron beam arise. The electron dose experienced by the sample can also be limited because a smaller probe size can be used.

Imaging and analysis of the sample were done using a sub-angstrom-sized probe with a probe current of approximately $68 \mathrm{pA}$, which was found to give the best balance of resolution, count rate, and sample stability. EDS was mainly used for compositional analysis due to the relative accessibility of the higher energy K-lines for $\mathrm{Ag}$ and $\mathrm{Pd}$, which enabled their easy identification due to sufficient separation between the respective $\mathrm{x}$-ray peaks. Another distinct advantage of the microscope is simultaneous acquisition of both bright field (BF) and high-angle annular dark field (HAADF) STEM images. This aided in the identification of grain boundaries in conjunction with elemental atomic number contrast imaging. The main objective of this investigation was to detect very low concentrations of Ag, Pd and other fission products by using high resolution TEM/STEM and an EDS system with a high collection efficiency.

\subsection{HRSTEM Investigation and Approach}

The Cs-corrected HRTEM was operated in scanning transmission mode, which allows for simultaneous viewing of BF and HAADF STEM images. This mode of viewing enables easy differentiation between $\mathrm{SiC}$ and $\mathrm{PyC}$ areas, as well as identification of fission product agglomerates in the form of nodules inside the $\mathrm{SiC}$ layer. The BF image provides sufficient contrast to identify the positions of grain boundaries and the presence of defects (such as stacking faults), which can then be correlated with the position of fission products by using HAADF imaging that shows atomic number $(Z)$ contrast. After HRSTEM imaging of the sites containing visible fission product agglomerates, EDS spot analysis was carried out on the fission products and surrounding areas to identify the elements present. Probe current conditions were chosen to optimize the beam current but, at the same time, minimize beam damage to the specimen.

\section{RESULTS}

\subsection{SiC as Main Barrier to Fission Products}

The effectiveness of the $\mathrm{SiC}$ layer as the main fission product barrier is illustrated by the HAADF STEM images in Fig. 4, where the accumulation of Pd at the IPyC-SiC interface is visible. Additionally, no significant $\mathrm{Pd}$ corrosion of $\mathrm{SiC}$ (i.e., only a few approximate 1-nm diameter corrosion pits) is observed at this high magnification, which confirms earlier SEM observations and proves that Pd can penetrate the $\mathrm{SiC}$ without corroding the surface significantly [11].

\subsection{Co-Existence of $A g, P d$, and $C d$ at Grain Boundaries and Triple Junctions}

$\mathrm{BF}$ and HAADF STEM images of fission product networks at $\mathrm{SiC}$ grain boundaries and triple points of specimen AGR-411-030 position 1b are shown in Fig. 5 (a) and (b), respectively. These fission product accumulations are visible as bright regions (i.e., high atomic number) in the HAADF STEM shown in Fig. 5 (b). Accumulations of $\mathrm{Pd}, \mathrm{Ag}$, and $\mathrm{Cd}$ were found to co-exist in the area indicated by the arrow marked 1 in the HAADF STEM image (b). The arrowed area 1 in Fig. 5(b) is shown at higher magnification in Fig. 6 as a BF STEM image of co-existing Pd-Ag-Cd accumulations at location 1 on a grain boundary between two $\mathrm{SiC}$ grains. Fig. 7 shows the EDS spectra at locations 1 to 3 in Fig. 6. The peaks for Ag and Cd passed the 2 sigma test as determined by the Oxford software. Thus the peaks are deemed to be statistically relevant. EDS analyses of locations 2 and 3 only indicated the presence of Pd.

Under certain imaging conditions, HAADF and BF STEM images are complementary; therefore, atom columns in dark field (DF) mode will change from bright spots to dark spots in BF mode. The dark spots at the grain boundary and at the triple points in Fig. 6 are due to the $\mathrm{Pd}, \mathrm{Ag}$, or $\mathrm{Cd}$ atoms. It is not possible to differentiate between these elements using BF STEM imaging. The EDS analyses caused slight damage to the atomic structure visible at the locations arrowed in Fig. 6.

Accumulations of Pd, Ag, and Cd co-exist in other areas of specimen AGR-411-030 position 1b, which was also confirmed by the HAADF STEM image shown in Fig. 8(a) with the corresponding EDS spectrum in Fig. 8 
(d). Only Pd Pd-U or Pd were found in the adjacent larger triple point accumulations (points 2 (spectrum Fig. 8(b) and 4 (spectrum Fig. 8(c)) respectively)indicated by arrow Pd). Higher magnification BF STEM images of the Pd-Ag-Cd containing triple points are shown in Fig. 9. In the BF STEM image, the fission products in the grain boundary and the triple point are visible as dark areas.

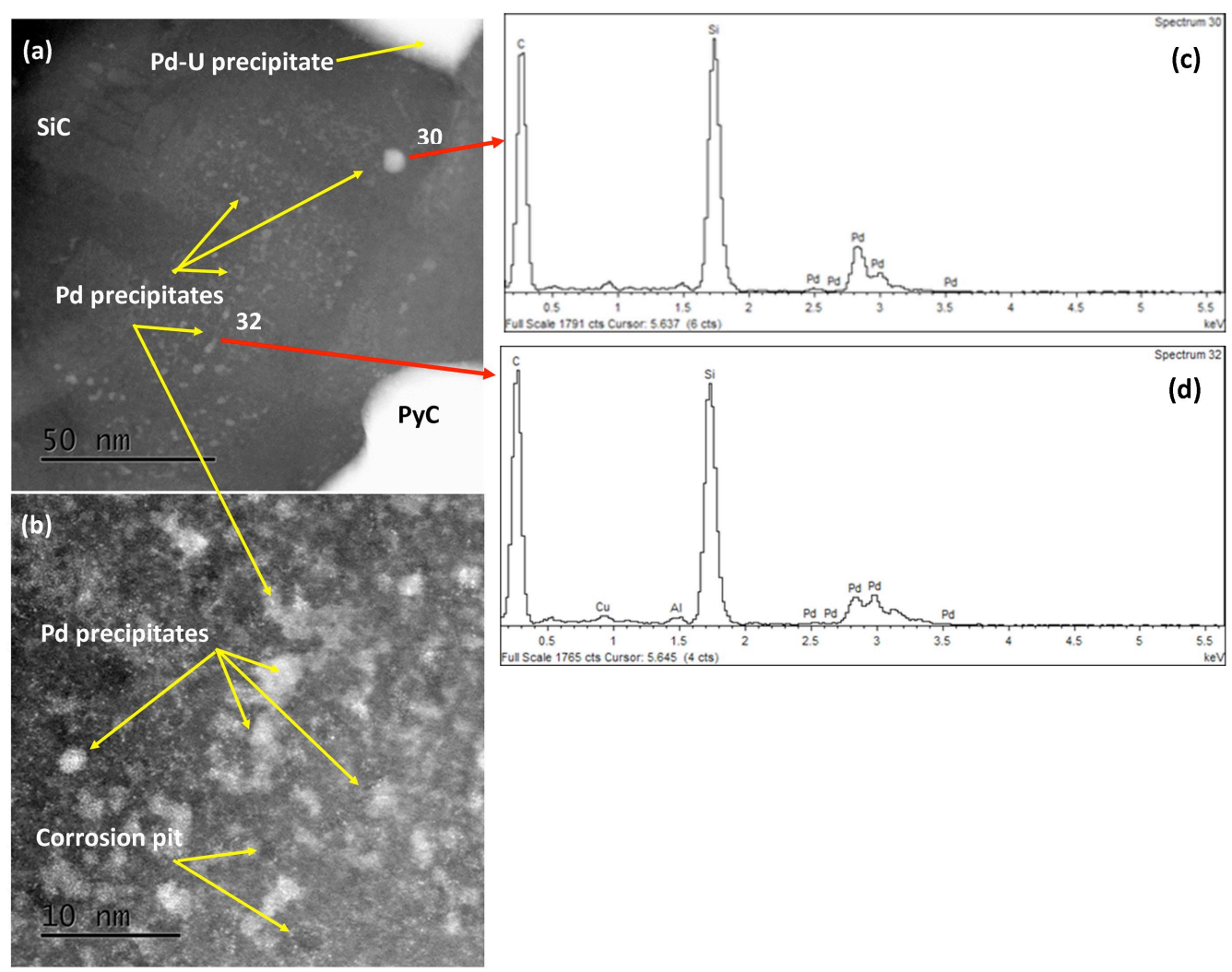

Fig. 4. HAADF STEM images showing (a) accumulation of Pd at the IPyC-SiC interface, (b) showing no significant corrosion except for a few approximate 1-nm diameter corrosion pits only visible at this magnification, and (c) and (d) showing the presence of Pd in two spectra of associated areas in (a) . 


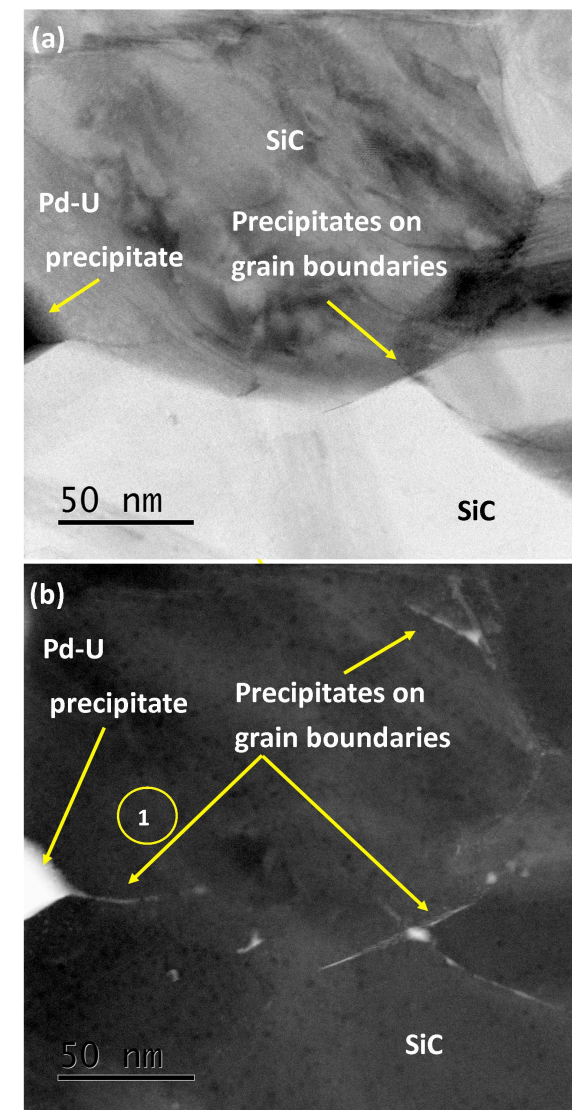

Fig. 5. BF (a) and dark field (b) STEM images of fission product networks at grain boundaries and triple points of specimen AGR-411-030 position 1b.

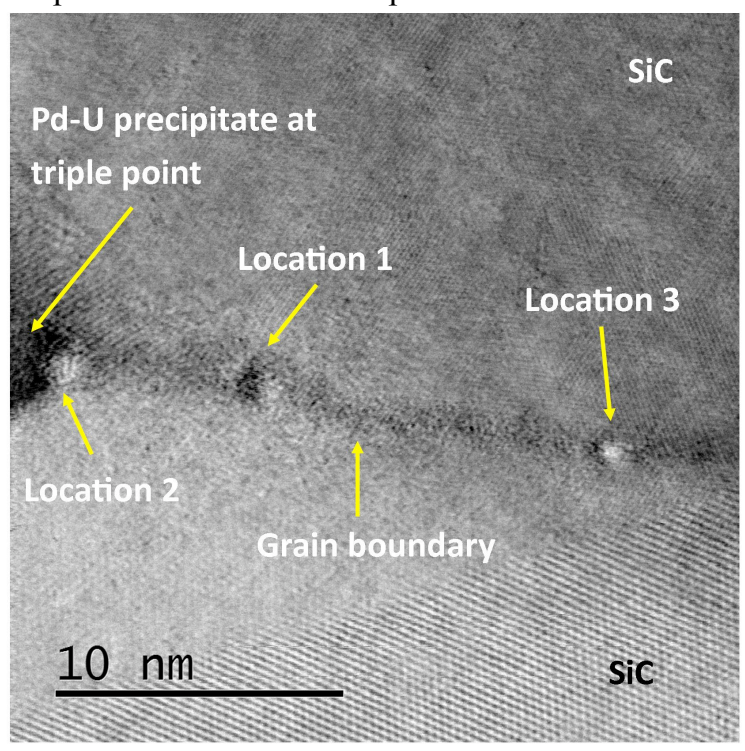

Fig. 6. High-resolution BF STEM image Pd-Ag-Cd accumulations co-existing at location 1 at a $\mathrm{SiC}$ grain boundary of specimen AGR-411-030 position 1b. Only Pd was found at locations 2 and 3. 

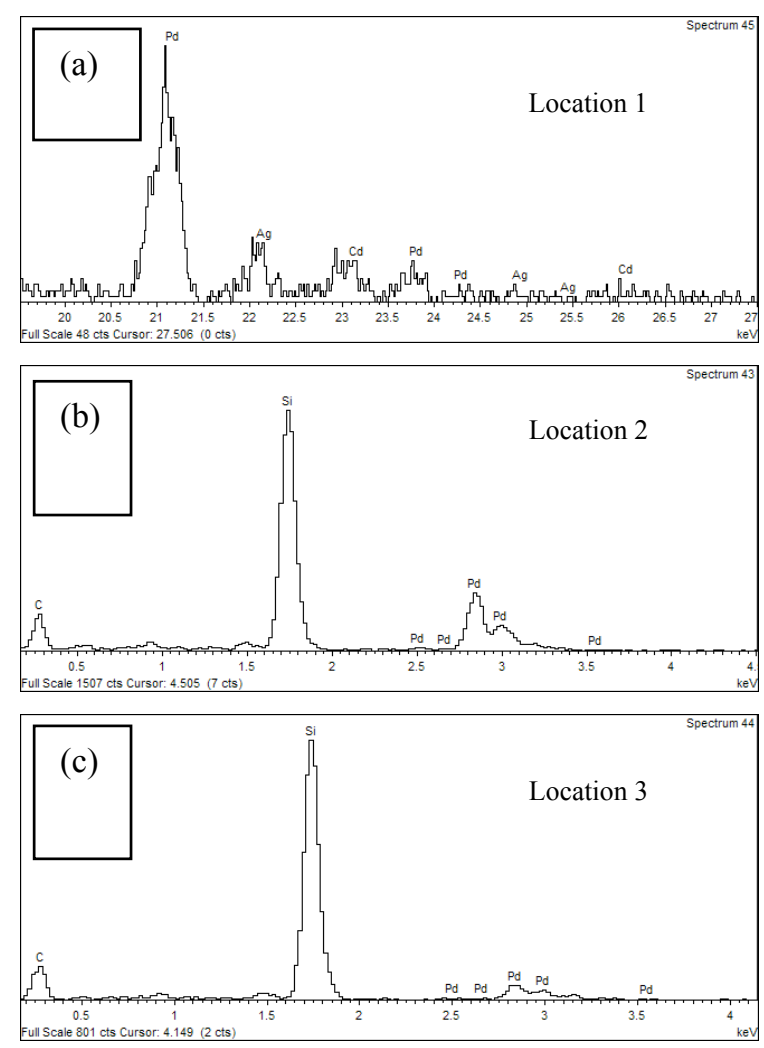

Fig. 7. EDS spectra showing (a) co-existence of $\mathrm{Pd}, \mathrm{Ag}$, and $\mathrm{Cd}$ at location 1 of specimen AGR-411-030 position $1 \mathrm{~b}$. The peaks for $\mathrm{Ag}$ and $\mathrm{Cd}$ passed the 2 sigma test as determined by the Oxford software. Thus the peaks are deemed to be statistically relevant, and showing that only Pd was found at locations 2 and 3 as shown in (b) and (c) 

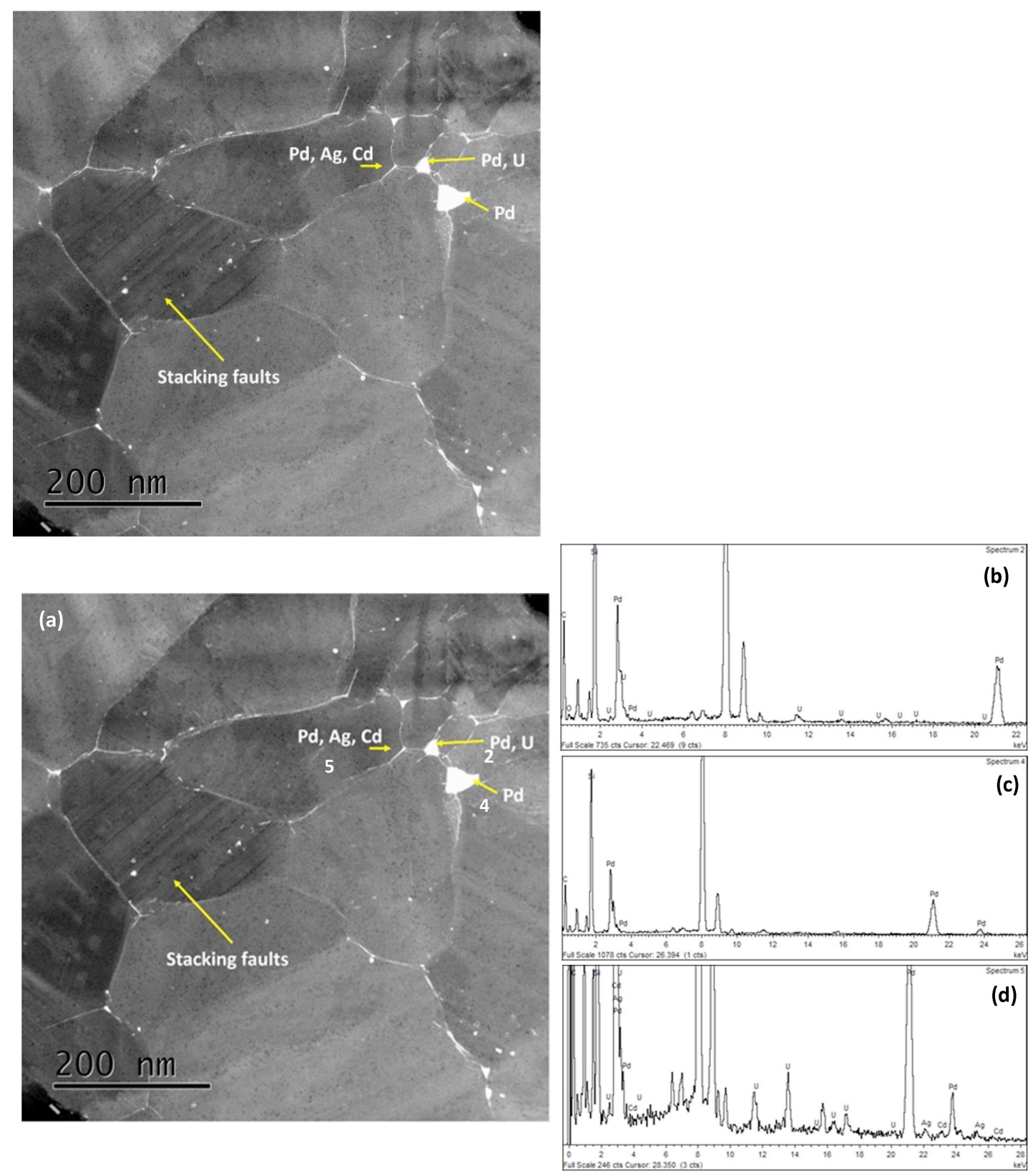

Fig. 8. Image showing (a) HAADF STEM image of specimen AGR-411-030 position 1b, showing a triple point where $\mathrm{Pd}, \mathrm{Ag}$, and Cd accumulations co-exist (point 5 in (a) and EDS spectrum in (d), Only Pd-U or Pd were 
found in the adjacent larger triple point accumulations (points 2 (spectrum (b) and 4 (spectrum (c)) respectively)


Fig. 9. BF STEM image (a) of a Pd-Ag-Cd containing triple point with the corresponding high-resolution BF STEM image (b).

$\mathrm{Ag}$ decay is suggested as the most likely primary source of $\mathrm{Cd}$ observed in the fission product nodules. Therefore, it is expected that at the end of irradiation, $\mathrm{Cd}$ will be present in close proximity to Ag. However, Cd is also a direct fission product (albeit one of lower yield and higher vapor pressure compared with $\mathrm{Ag}$ and $\mathrm{Pd}$ ) and it is possible that some of the Cd observed could have been created by fission.

\subsection{Intragranular Presence of $\mathrm{Pd}$ in $\mathrm{SiC}$}

$\mathrm{Pd}$ was also observed inside $\mathrm{SiC}$ grains in proximity to planar defects such as stacking faults or nano twins (see Fig. 10). This is an interesting observation because the majority of the Pd nodules are usually found along $\mathrm{SiC}$ grain boundaries. However, it is proposed that the same mechanism that governs the movement of Pd along $\mathrm{SiC}$ grain boundaries is responsible for the migration of $\mathrm{Pd}$ along planar defects in $\mathrm{SiC}$. Grain boundaries contain high concentrations of dislocations due to the relative misorientation between adjacent grains; therefore, they have a comparatively open structure. This results in diffusivities for grain-boundary transport that are much larger than analogous values for lattice diffusion. Enhanced diffusion along dislocation cores will also occur. SiC grains containing high concentrations of stacking faults (or nano-twins) bounded by partial dislocations will also have a high concentration of easy diffusion paths created by the stacking faults and partial dislocation cores. This is consistent with the work of Kornilios et al. [16] who suggested that the observed diffusion of gold through a $2.8-\mu \mathrm{m}$ thick $3 \mathrm{C}-\mathrm{SiC}$ layer at $500^{\circ} \mathrm{C}$ for 500 hours was most likely along stacking faults extending through the layer.

As mentioned earlier, stacking faults and nano-twins also provide easy diffusion paths for atoms and may explain the presence of $\mathrm{Pd}$ at stacking faults (or nano-twins) inside the $\mathrm{SiC}$ grains observed in this study. 




Fig. 10. BF STEM image in (a) showing the position of the Pd accumulation at a stacking fault in a $\mathrm{SiC}$ grain with ahigh resolution BF STEM image in (b) with the corresponding EDS spectrum in (c).

\subsection{Penetration Depth and Compositional Identification of Fission Products in the SiC Layer}

Because significant $\mathrm{Ag}$ was released from this particle, it was our aim to identify locations of Ag through the the $\mathrm{SiC}$ layer in an attempt to correlate the locations with local microstructure (e.g., grain size and grain boundary character). Determination of the maximum penetration depth in $\mathrm{SiC}$ is challenging because the $\mathrm{Pd}$ nodules that are clearly visible at low magnification are not visible at the maximum penetration depth. (This is specifically a limitation when SEM analysis is used to determine the fission product depth.) When the magnification is increased, smaller hairline (i.e., about 1 to 2-nm thick) networks of Pd become visible and extend further into the $\mathrm{SiC}$ than the larger nodules that are easily observed at lower magnification. EDS analyses of these hairline networks also become challenging when the concentration of $\mathrm{Pd}$ or $\mathrm{Ag}$ is of the same magnitude as the EDS detection limit. From this depth and deeper into the $\mathrm{SiC}$, atomic migration along the grain boundaries below the STEM and EDS detection limits is possible and quite likely.

Pd was found to be present in nodule networks throughout FIB lamellas 1b, 1c, and 2 (work by Lillo et al. [17] shows networks of Pd through the total SiC layer thickness for a particle from Compact 6-3-2 irradiated to $11.4 \%$ fissions per initial metal atom). In this particle, $\mathrm{Ag}$ is found at a distance of about $6.7 \mu \mathrm{m}$ from the IPyC$\mathrm{SiC}$ interface (Fig. 11 and Fig. 12 for higher magnification of this area) in this specific lamella 1b (no Ag was measured in lamella 1c). This value should be considered as a lower (i.e., detectable) limit for the current irradiation conditions of the TRISO particle and electron microscopy techniques employed for this investigation. However, Ag has only been found together with Pd and Cd. Although electron energy loss spectroscopy has a better spatial resolution than EDS, it is not ideal in this case for analysis of Ag due to edge overlap. 




Fig. 11. BF STEM image of SiC showing the penetration depth of Ag measured in this specific SiC lamella $1 \mathrm{~b}$ (no Ag was measured in lamella 1c).

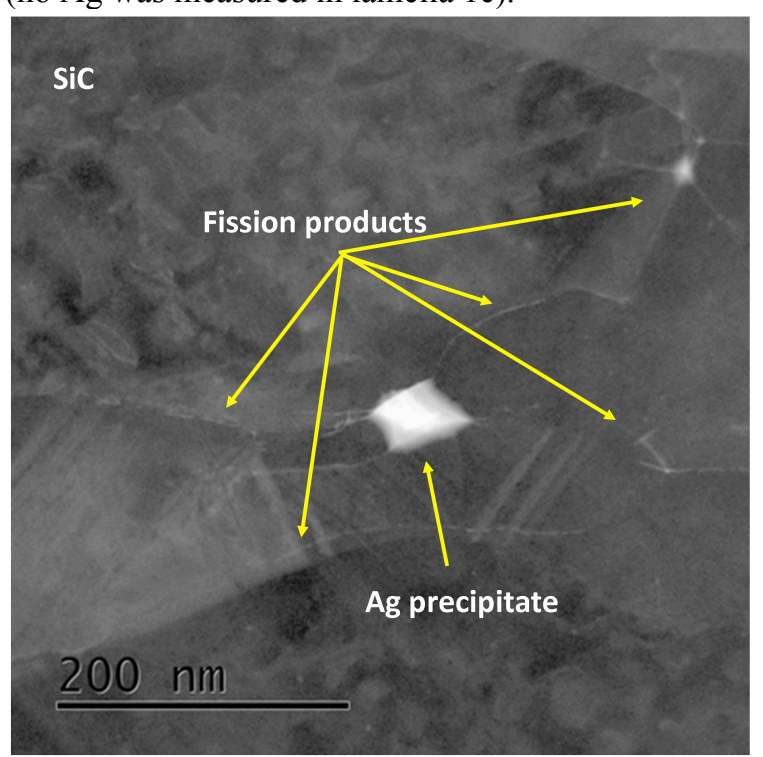

Fig 12 BF STEM image of SiC showing the penetration depth of Ag at higher magnification. At this larger magnification, more fission product triple points are visible.

\subsection{EDS Analysis Using the JEOL Centurio EDS Detector}

More detailed EDS analysis was performed on AGR1-411-030 using a next generation EDS detector. In the area shown in Figure 13, Ag was found to be co-existing with Pd at EDS points 1 through 4 and was corresponding to grain boundaries and triple points. Figure 14 shows the presence of $\mathrm{Ag}$ at location point 4. Neither $\mathrm{Ag}$ nor $\mathrm{Pd}$ were found at points 5 and 6 , which were inside the $\mathrm{SiC}$ grains. However, phosphorus $(\mathrm{P})$ was detected in association with $\mathrm{Pd}$ and $\mathrm{Ag}$ at the $\mathrm{SiC}$ grain boundary at point 1 while in contrast no $\mathrm{P}$ was detected in the $\mathrm{SiC}$ grain at positions 5 and 6 (Figure 15). Further analysis on grain boundaries at an additional site revealed also $P$ on grain boundaries as shown in Fig. 16, specifically at points 1 and 2. This suggests segregation of $\mathrm{P}$ at the boundaries and triple points. The software identifies and quantifies it to be within a 3 sigma level. This is the first finding of $\mathrm{P}$, which is usually produced by neutron transmutation of silicon, in the SiC layer grain boundaries of neutron-irradiated, TRISO-coated particles. 


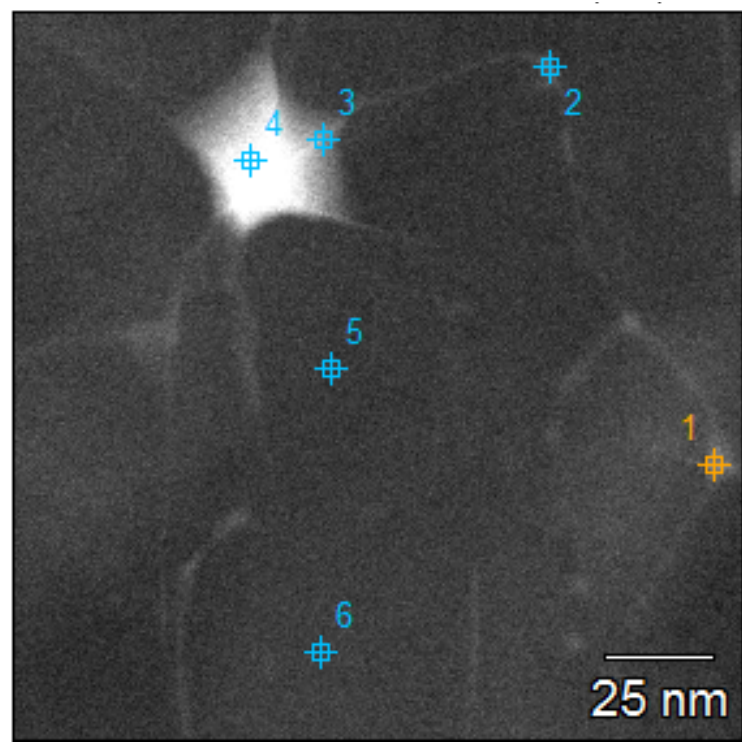

Fig. 13. Selected HRSTEM image showing the six locations where EDS analysis was completed using the new higher-resolution EDS detector.

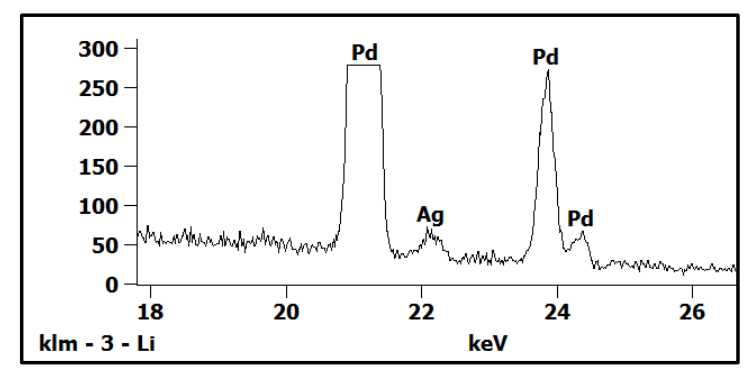

Fig. 14. HRSTEM-EDS spectrum at point 4 showing the co-existence of $\mathrm{Ag}$ and $\mathrm{Pd}$.

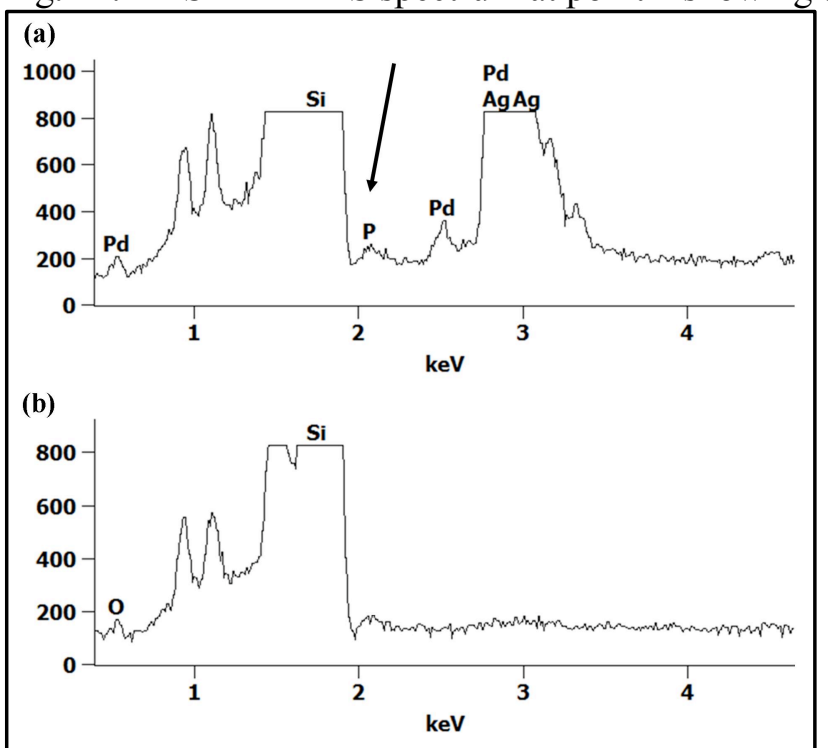

Fig. 15. HRSTEM-EDS spectra at points 1(a) and 5(b) showing the presence of $\mathrm{P}$ (as indicated by the arrow) at the grain boundary but not in the $\mathrm{SiC}$ grain respectively. 


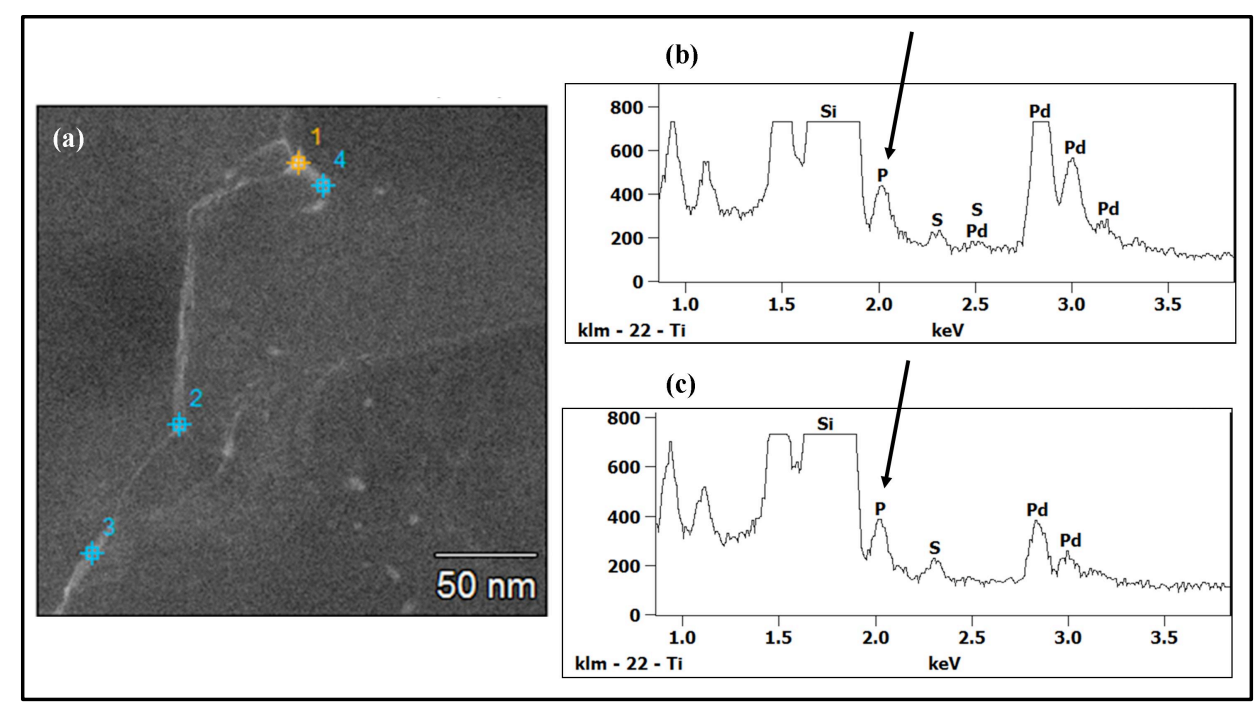

Fig. 16. Selected HRSTEM image (a) showing the four locations where EDS analysis was completed using the new higher-resolution EDS detector. HRSTEM-EDS spectra at points 1(b) and 2(c) showing the presence of $\mathrm{P}$ (as indicated by the arrow) at the grain boundary triple points.

\section{DISCUSSION AND CONCLUSIONS}

This paper describes some of the first analytical HRSTEM results obtained from examination of a particle from Compact 4-1-1, which was irradiated to an average burnup of $19.38 \%$ fissions per initial metal atom; a time-averaged, volume-averaged temperature of $1072^{\circ} \mathrm{C}$; a time-averaged peak temperature of $1182^{\circ} \mathrm{C}$; and an average fast fluence of $4.13 \times 10^{21} \mathrm{n} / \mathrm{cm}^{2}$. Based on gamma ray analysis, it is estimated that this particle may have released as much as $10 \%$ of its available Ag-110m inventory during irradiation.

With STEM imaging, Pd accumulation at the IPyC-SiC interface was observed, which is an indication that $\mathrm{Pd}$ diffuses rapidly through the $\mathrm{PyC}$ layers until it reaches the $\mathrm{SiC}$, where transport is much slower. This confirms the effectiveness of the $\mathrm{SiC}$ layer and the morphology of the $\mathrm{IPyC} / \mathrm{SiC}$ interlayer as the main fission product barrier. Additionally, no significant $\mathrm{Pd}$ corrosion of $\mathrm{SiC}$ was observed, which confirmed earlier SEM observations and indicated that $\mathrm{Pd}$ can penetrate the $\mathrm{SiC}$ without significantly corroding the surface.

$\mathrm{BF}$ and HAADF STEM images of fission product networks at $\mathrm{SiC}$ grain boundaries and triple points of specimen AGR-411-030 indicated that accumulations of $\mathrm{Pd}, \mathrm{Ag}$, and $\mathrm{Cd}$ co-existed at grain boundaries and triple points. At some locations, EDS analyses only indicated the presence of Pd. However, the possible presence of $\mathrm{Ag}$ or $\mathrm{Cd}$ at these locations in concentrations below the EDS detection limit cannot be ruled out. Ag decay is most likely the primary source of the $\mathrm{Cd}$ observed in the fission product nodules. Therefore, $\mathrm{Cd}$ is expected to be present in close proximity to $\mathrm{Ag}$ at the end of irradiations. If $\mathrm{Cd}$ accumulations were observed without any $\mathrm{Ag}$, it could have indicated a source of $\mathrm{Cd}$ was fission in the kernel.

Pd was also observed inside $\mathrm{SiC}$ grains in proximity to planar defects such as stacking faults or nano twins. This is an interesting observation because the majority of Pd precipitates are usually found along $\mathrm{SiC}$ grain boundaries. Previous STEM work by Van Rooyen et al. [13] showed the presence of spherical nano Pd precipitates inside grains as well; it was not possible to provide more positional information of these $\mathrm{Pd}$ precipitates inside the $\mathrm{SiC}$ grains, although evidence of fission products were found comparing HAADF with corresponding $\mathrm{BF}$ images (it was not possible to obtain compositional quantification and identification of these precipitates due to its low concentration). This HRTEM study provides this new information. It is proposed that the same mechanism that governs movement of $\mathrm{Pd}$ along $\mathrm{SiC}$ grain boundaries is responsible for migration of $\mathrm{Pd}$ along planar defects in SiC. Grain boundaries contain high concentrations of dislocations due to relative misorientation between adjacent grains; therefore, they have a comparatively open structure. This results in diffusivities for grain-boundary transport that are much larger than analogous values for lattice diffusion. Enhanced diffusion along dislocation cores will also occur. SiC grains containing high concentrations of stacking faults (or nano-twins) bounded by partial dislocations will also have a high concentration of easy diffusion paths created by the stacking faults and partial dislocation cores.

Furthermore, the transport of $\mathrm{Pd}$ in $\mathrm{SiC}$ is proposed to be mediated by a silicide formation mechanism at temperatures in the range of $1000^{\circ} \mathrm{C}$. At temperatures above the melting point of the silicide (i.e., about $980^{\circ} \mathrm{C}$ for $\mathrm{Pd} / \mathrm{Si}$ ), $\mathrm{Si}$ atoms will diffuse into the $\mathrm{Pd}$ nodule via an exchange mechanism with $\mathrm{Pd}$ atoms, which will release more $\mathrm{Pd}$ atoms to penetrate the $\mathrm{SiC}$ and react with $\mathrm{Si}$ atoms at the grain boundaries. For this reason, migration of Pd is seen to occur preferentially along grain boundaries. As mentioned earlier, stacking faults and 
nano-twins also provide easy diffusion paths for atoms and may explain the presence of Pd at stacking faults (or nano-twins) inside the $\mathrm{SiC}$ grains observed in this study. Earlier work on irradiated TRISO-coated particles [11] also revealed the alignment of voids at the grain boundaries in the vicinity of fission product precipitates.

With increased magnification, smaller hairline networks of $\mathrm{Pd}$ become visible and extend deeper (i.e., frequently up to $8 \mu \mathrm{m}$ ) into the $\mathrm{SiC}$ than the larger nodules that are easily observed at lower magnification. From this depth and deeper into the $\mathrm{SiC}$, atomic migration along the grain boundaries, below the STEM and EDS detection limits, is possible and quite likely.

However, $\mathrm{Ag}$ has only been found together with $\mathrm{Pd}$ and $\mathrm{Cd}$ for samples from this specific compact and the current irradiation conditions. Ag being found inside $\mathrm{SiC}$ at grain boundaries only in the presence of $\mathrm{Pd}$ is consistent with the Pd-assisted transport mechanism proposed by Neethling and co-workers [5]. This may also explain why the majority of the out-of-pile experiments carried out to determine the diffusion coefficient of Ag in $\mathrm{SiC}$ did not reveal any significant $\mathrm{Ag}$ migration in $\mathrm{SiC}$. The first finding of $\mathrm{P}$ in the SiC layer of neutronirradiated, TRISO-coated particles is reported in this work. $\mathrm{P}$ is usually produced by neutron transmutation of silicon. No direct link between the presence of P and Ag transport could be made from this study.

Although the results of this analytical HRSTEM study are consistent with a Pd-assisted Ag transport mechanism along grain boundaries, more research is needed to elucidate the effect of neutron irradiation damage (and irradiation temperature) on fission product transport at the nano and atomic level, which is one of the research focus areas at Idaho National Laboratory.

\section{ACKNOWLEDGEMENTS}

This work was sponsored by the U.S. Department of Energy Office of Nuclear Energy under the Department of Energy Idaho Operations Office Contract DE-AC07-05ID14517. James Madden is acknowledged for FIB sample preparation. David Petti, Paul Demkowicz, and Jack Simonds are thanked for their review of this document. The Centre for HRTEM in South Africa gratefully acknowledges the Department of Science and Technology, the National Research Foundation, and Sasol for their financial support.

6. REFERENCES

[1] Nabielek, H., P. E. Brown, and P. Offerman, 1977, "Silver Release from Coated Particle Fuel," Nucl. Techn. 35: 483.

[2] MacLean, H. J., R. G. Ballinger, L. E. Kolaya, S. A. Simonson, N. Lewis, and M. E. Hanson, 2006, "The Effect of Annealing at $1500^{\circ} \mathrm{C}$ on Migration and Release of Ion Implanted Silver in CVD Silicon Carbide," J. Nucl. Mater. 357: 31-47.

[3] Friedland, E., J. B. Malherbe, N. G. Van der Berg, T. Hlatshwayo, A. J. Botha, E. Wendler, and W. Wesch, 2009, "Study of Diffusion in Silicon Carbide," J. Nucl. Mater. 389: 326-331.

[4] Lopez, E., D. Honorato, X. Yang, J. Tan, P. J. Meadows, and P. Xiaow, 2010, "Silver Diffusion in Coated Fuel Particles," J. Am. Ceram. Soc. 93(10): 3076-3079.

[5] Olivier, E. J. and J. H. Neethling, 2012, "Palladium Transport in SiC," Nucl. Eng. and Design 244: $25-33$.

[6] Neethling, J. H., J. H. O'Connell, and E. J. Olivier, 2012, "Palladium Assisted Silver Transport in Polycrystalline SiC," Nucl. Eng. and Design 251: 230-234.

[7] Olivier E. J. and J. H. Neethling, 2013, “The Role of Pd in the Transport of Ag in SiC," J. Nucl. Mater. 432: 252-260.

[8] Schrader, D., S. M. Khalil, T. Gerzcak, T. R. Allen, A. J. Heim, I. Szlufarska, and D. Morgan, 2011, “Ag Diffusion in Cubic Silicon Carbide," J. Nucl. Mater. 408: 257-271.

[9] Khalil, S., N. Swaminathan, D. Schrader, A. J. Heim, D. D. Morgan, and I. Szlufarska, 2011, "Diffusion of Ag Along Grain Boundaries in 3C-SiC," Physical Review B 84: 214104.

[10] O'Connell, J. H. and J. H. Neethling, 2014, "Ag Transport in High Temperature Neutron Irradiated 3CSiC," J. Nucl. Mater. 455: 20-25.

[11] van Rooyen, I. J., D. E. Janney, B. D. Miller, P. A. Demkowicz, and J. Riesterer, 2014, "Electron Microscopic Evaluation and Fission Product Identification of Irradiated TRISO Coated Particles from the AGR-1 Experiment," A Preliminary Review, Nucl. Eng. and Design 271: 114-122.

[12] Demkowicz, P. A., J. D. Hunn, S. A. Ploger, R. N. Morris, C. A. Baldwin, J. M. Harp, P. L. Winston, T. Gerczak, I. J. van Rooyen, F. C. Montgomery, and C. M. Silva, 2014, "Irradiation Performance of AGR1High Temperature Reactor Fuel,” Nucl. Eng. Des. (2015), http://dx.doi.org/10.1016/j.nucengdes.2015.09.011, in press

[13] van Rooyen, I. J., T. M. Lillo, and Y. Q. Wu, 2014, "Identification of Silver and Palladium in Irradiated TRISO Coated Particles of the AGR-1 Experiment," J. Nucl. Mater. 446: 178-186.

[14] Maki, J. 2009, AGR-1 Irradiation Experiment Test Plan, INL/EXT-05-00593, Revision 3, Idaho National Laboratory, October 20, 2009.

[15] Demkowicz, P. A., J. M. Harp, P. L. Winston, S. A. Ploger, I. J. van Rooyen, B. D. Miller, and J. Reisterer, 2015, “AGR-1 Compact 4-1-1 Post-Irradiation Examination,” INL/EXT-15-36169, 2016. 
[16] Kornilios, N., G. Constantinidis, M. Kayiambaki, K. Zekentes, and J. Stoemenos, 1997, "Diffusion of Gold in 3C-SiC Epitaxially Grown on Si: Structural Characterization," Mat. Sci. Eng. B 46: 186-189

[17]Lillo, T. and I. J. van Rooyen, 2015, "Distribution of Pd, U, and Ag in the SiC Layer of Irradiated TRISO Fuel,” J. Nucl. Mater. Vol. 460 pp. 97-106, May 2015. 